\title{
Helen Palmer
}

\section{Jellyfish}

\begin{tabular}{|c|c|c|c|}
\hline $\begin{array}{l}\text { half-moon } \\
\text { half-bubble } \\
\text { invert }\end{array}$ & $\begin{array}{l}\text { rings that meet } \\
\text { and shoot you } \\
\text { through the } \\
\text { deep }\end{array}$ & $\begin{array}{l}\text { but at low tide } \\
\text { when your skin } \\
\text { meets the } \\
\text { outside's }\end{array}$ & $\begin{array}{l}\text { while } \\
\text { submerged } \\
\text { your inside is } \\
\text { outside but in }\end{array}$ \\
\hline $\begin{array}{l}\text { you make one } \\
\text { cell an } \\
\text { everywhere }\end{array}$ & $\begin{array}{l}\text { your skin is a } \\
\text { muscle that }\end{array}$ & $\begin{array}{l}\text { outside it } \\
\text { should keep } \\
\text { your insides }\end{array}$ & $\begin{array}{l}\text { the outside you } \\
\text { are wrong }\end{array}$ \\
\hline $\begin{array}{l}\text { your one silent } \\
\text { bell is the crust } \\
\text { of your world }\end{array}$ & $\begin{array}{l}\text { flips you nearly } \\
\text { inside out just } \\
\text { flipping to } \\
\text { scoosh yourself }\end{array}$ & $\begin{array}{l}\text { but at some } \\
\text { point you were }\end{array}$ & $\begin{array}{l}\text { when your } \\
\text { insides meet } \\
\text { my outside }\end{array}$ \\
\hline $\begin{array}{l}\text { our } \\
\text { lovetailing }\end{array}$ & $\begin{array}{l}\text { over and over } \\
\text { an underwater } \\
\text { arabesque with }\end{array}$ & $\begin{array}{l}\text { flipped rather } \\
\text { than flipping as } \\
\text { dancing }\end{array}$ & $\begin{array}{l}\text { naked and } \\
\text { upturned }\end{array}$ \\
\hline $\begin{array}{l}\text { movements of } \\
\text { contraction and } \\
\text { expansion form } \\
\text { two rippling }\end{array}$ & $\begin{array}{l}\text { fleshy ribbons } \\
\text { trailing a } \\
\text { stinging wake }\end{array}$ & $\begin{array}{l}\text { through water } \\
\text { you flip }\end{array}$ & you are a splat \\
\hline
\end{tabular}

